\title{
Once daily baclofen sustained release or gastro-retentive system are acceptable alternatives to thrice daily baclofen immediate release at same daily dosage in patients
}

Nitin G. Sampat, Rahul V. Kulkarni ${ }^{1}$, Nathaniel Sase ${ }^{2}$, Nishith H. Joshi ${ }^{3}$, Pragnesh B. Vora ${ }^{4}$, Amal K. Bhattacharya ${ }^{5}$, J. D. Lakhani ${ }^{6}$, Shravanti S. Bhowmik ${ }^{7}$

Breach Candy Hospital, Matru Mandir, 278 Tardeo Road, Mumbai - 400 007, ${ }^{1}$ Department of Neurology, Dinanath Mangeshkar Hospital and Research Center, Pune - 411 004, ${ }^{2}$ Department of Neurology, Wanless Hospital, Miraj-416 410, ${ }^{3}$ Sheth V. S. General Hospital, Aarsi Corner, Ellisbridge, Ahmedabad - 380 006, ${ }^{4}$ B. J. Medical College, Ahmedabad - 382 443, ${ }^{5}$ Government Medical College, Surat- 395 001, ${ }^{6}$ Department of Medicine, Pramukbswami Medical College, Karamsad - 388 325, ${ }^{7}$ Clinical Research, Sun Pharma Ltd., Mumbai - 400 093, India

\author{
Address for correspondence: \\ Dr. Shravanti S. Bhowmik \\ C-11, Symphony CHS Ltd., \\ Chandivili, Powai, \\ Mumbai - 400 072, India. \\ E-mail: shravantib@gmail.com
}

\begin{abstract}
Background: Baclofen, a GABA-agonist, is currently available as an immediate release (IR) formulation for relieving neurogenic spasticity in a variety of disorders. Baclofen IR requires to be administered three times a day which inadvertently increases the chances of medication noncompliance among patients and is also associated with side effects such as drowsiness and muscle weakness. Aim: To overcome the shortcomings of baclofen IR, two modified formulations, baclofen sustained release (SR) and gastric retentive system (GRS), have been proposed to be equivalent in efficacy to baclofen IR with the administration of a single daily dose. Materials and Methods: Ninety patients with chronic neurogenic muscular spasticity were enrolled requiring 10-20 mg of baclofen IR every eight hours. The patients were randomized to two treatment arms: SR $(n=46)$ or GRS $(n=44)$ at the same once-daily dose for four weeks. Efficacy was measured by Ashworth score for muscle tone, spasm score, reflex score, 30-item functional independence score, and patient's diary score for three most affected activities of daily life. Results: The mean Ashworth score changed significantly $(P=0.00)$ for patients in the SR group from $3.03-2.69(-0.35)$ and 3.07-2.70 $(-0.37)$ for patients in the GRS group. There was no significant difference $(P=0.87)$ between baseline-adjusted Ashworth score reductions on SR $(-0.35)$ and GRS $(-0.37)$. Similar results were obtained for spasm, reflex, and functional independence scores. The mean baseline-adjusted patient-diary scores did not differ significantly between $8 \mathrm{am}, 12 \mathrm{pm}, 4 \mathrm{pm}$, and $8 \mathrm{pm}(P=0.96)$, either on SR $(-5.3$ to -6.1$)$ or GRS $(-7.3$ to -8.1$)$, indicating a uniform effect round-the-day on both. Further, sedation scores (mean \pm SEM) decreased significantly $(P<0.05)$ on both SR (10.36 \pm 1.37 to $6.18 \pm 0.92)$ and GRS $(8.14 \pm 1.57$ to $5.33 \pm 1.11)$, suggesting better toleration. Conclusion: Once-daily baclofen SR and GRS are efficacious, convenient, and better-tolerated alternatives to baclofen IR in patients with neurogenic spasticity.
\end{abstract}

Key words: Ashworth, baclofen, gastroretentive, spasticity, sustained 


\section{Introduction}

Baclofen, a derivative of gamma-aminobutyric acid (GABA), is indicated in the alleviation of signs and symptoms of spasticity resulting from multiple sclerosis, particularly for the relief of flexor spasms and concomitant pain, clonus, and muscular rigidity. ${ }^{[1]}$ Clinical studies with baclofen have indicated that its major site of action is the spinal cord..$^{[2]}$ However it has been used in patients with spasticity of cerebral origin. ${ }^{[3,4]}$ Spasticity is one of the components of the upper motor neuron (UMN) syndrome but should not be considered in isolation when it comes to management strategies. ${ }^{[5]}$ Baclofen is used as a muscle relaxant and an antispastic agent for a variety of neurological disorders. It is a GABA-B receptor agonist that depresses the monosynaptic and polysynaptic excitation of mononeurons and interneurons. ${ }^{[1]}$ Currently, the most commonly used dose form for baclofen is the immediate release (IR) tablet (10-20 $\mathrm{mg}$ ) to be administered three times a day. A serum concentration of $80 \mathrm{ng} / \mathrm{mL}$ or more is considered an effective concentration. ${ }^{[4]}$ Because higher doses often cause side effects such as drowsiness, dizziness, and muscle weakness, a dose of $10 \mathrm{mg}$ is used in most patients as it provides enough symptomatic relief with minimal side effects. Also, the frequent administration of conventional baclofen IR tablets leads to fluctuations in plasma concentration, producing peaks and troughs. The peaks are associated with side effects, such as drowsiness, dizziness, and muscle weakness, and troughs are associated with inadequate control of muscle spasm. These side effects are considered as major deterrents to the prescribers for up-titration of the dosage for optimization of therapy. In addition, as baclofen IR has to be taken three times a day, medication noncompliances are not rare occurrences. The latter factor of noncompliance can be overcome by the prescription of medications that require a minimal number of doses. A once-a-day dosage formulation with the same therapeutic effectiveness as the baclofen IR tablet would vastly improve patients' compliance with treatment. This will increase the outcome of therapy, as more number of patients will adhere to treatment plan. There are two modified formulations of baclofen, ${ }^{[6]}$ sustained release (SR) tablets and gastroretentivesystem (GRS) capsules, which satisfy the investigational criteria as a replacement therapy for baclofen IR. Both these formulations are designed to release one-third of their baclofen content immediately to achieve an effective plasma concentration, which varies from $80-400 \mathrm{ng} / \mathrm{mL}^{[7]}$, and the remainder over several hours to sustain it. Evidence suggests that baclofen is transported from the gastrointestinal tract via a natural amino-acid transport system that is preferentially distributed in the proximal part of the small intestine and like other transporter systems can be saturated.
To capitalize on the localization of transporter proteins responsible for baclofen absorption, baclofen SR and GRS are designed to prolong retention of a drug reservoir within the stomach and thus provide slow release of baclofen to the small intestine. This could translate into better clinical efficacy at the same total daily dose as baclofen IR as evidenced by improved Ashworth score. In previous exploratory clinical trials, successful switching over of patients from conventional baclofen IR tablets to a new formulation of baclofen SR (once-daily dose) was achieved with improvement in safety, efficacy, and tolerability profiles of baclofen SR formulations. The present study was designed to assess whether patients taking baclofen IR tablets (30-60 mg/day) could be switched over to modified release formulations such as baclofen SR and baclofen GRS once daily at equivalent doses without changes in efficacy. The trial was also aimed to find the difference in the tolerability, if any, between the three treatments (baclofen IR/baclofen SR/ baclofen GRS).

\section{Materials and Methods}

The study was conducted in the outpatient clinics at seven sites between January and December 2005. An Independent Ethics Committee approved the study. The study was conducted in conformity with ethical principles that have their origin in the Declaration of Helsinki. All patients were required to sign an informed consent before participation in the study. This was a randomized (1:1), controlled, parallel-group, double-blind, multicenter study with a total of 90 patients (minimum four patients per clinic), males and females aged $18-65$ years, who had chronic, neurogenic muscular spasticity requiring $10-20 \mathrm{mg}$ of baclofen IR eight hourly, with an Ashworth score of about 3. Pregnant women or women of reproductive age unable or unwilling to use effective contraception; patients using concomitant medications likely to influence muscle tone; gastrointestinal disorder likely to affect transport or dissolution of baclofen SR or GRS; clinical or investigational evidence of gross cardiovascular, hepatic, renal, or hematological abnormality; and participation in any clinical trial during the preceding four weeks were excluded. A computer-generated randomization system was provided by clinical research personnel not involved in the design, conduct, or analysis of the trial. The patients were assigned randomly to either SR or GRS in blocks of four at each center. There were three strengths of SR tablets and GRS capsules - 30, 45, and $60 \mathrm{mg}$. Each patient was asked to take one tablet or capsule daily after breakfast corresponding to current dose of IR -10,15, or $20 \mathrm{mg}$ eight hourly, respectively, - for four weeks [Table 1].

Compliance was measured by counting the number of tablets or capsules dispensed and returned. The patients 
were seen on five occasions: Day 0 (screening), day 3 (baseline), day 10, day 17, and day 31. Efficacy was measured by: 5-point Ashworth scale ${ }^{[8]}$ for muscle tone (1 (normal tone) to 5 (rigid and fixed)); spasm score ${ }^{[9]}$ (0 (none) to 4 (>10/hour)); reflex score (0 (absent) to 5 (clonus)); a 30-item functional independence score (1 (totally assisted) to 7 (totally independent) for each item); clinical global improvement score (1 (very much improved) to 7 (very much worse)); and patient's diary score with a range from 0 (complete independence) to 100 (total assist), to be rated four times a day -8 am (before morning dose), $12 \mathrm{pm}, 4 \mathrm{pm}$, and $8 \mathrm{pm}$ for a period of 30 days. These measurements were made on day 3 (baseline) and on days 10,17 , and 31 . Note was also made of any intercurrent illness and treatment for it. Safety was monitored by recording all adverse events and by clinical chemistry on days 3 and 31 . Baclofen is known to cause sedation. Sedation was scored at each visit by the physician on a line analog rating scale marked from 0 (no sedation) to 100 (extreme sedation). The patient was verbally asked to rate the extent of sedation felt and this was noted by the investigator in the case record form (CRF). Statistical analysis was performed by paired $t$ test for significant change in each group and student's $t$-test for between-groups differences. Equivalence was defined as a change in mean Ashworth score from day 0 (baseline) to day 31 , not exceeding $20 \%$ of the baseline value. A sample size of 38 per group would provide a power of $80 \%$ to detect a difference of this size at a two-sided significance level of $5 \%$. To provide for possible attritions, 45 were enrolled on each medication. The changes in means of patient diary scores between the 4-time points were compared by analysis of covariance (ANCOVA), using baseline score as the covariate, and Scheffe's test for multiple comparisons. Results were expressed as means (95\% confidence intervals or $\mathrm{CI}$ ) or as means \pm standard errors of means (SEM). Stata 8.2 software was used for the statistical analysis.

\section{Results}

Of the 90 patients enrolled, 46 patients were randomized to baclofen SR and 44 assigned to baclofen GRS. However, one on SR was excluded from analysis because of $<80 \%$ compliance, and one assigned to GRS did not return after day 3 . Hence, per-protocol analysis was done

\begin{tabular}{lcc}
\hline \multicolumn{3}{l}{$\begin{array}{l}\text { Table I: Dose of baclofen sustained release or gastroretentive } \\
\text { system for switchover from baclofen immediate release }\end{array}$} \\
\hline $\begin{array}{l}\text { Baclofen IR tablet } \\
\text { (mg T.I.D.) }\end{array}$ & $\begin{array}{r}\text { Baclofen SR } \\
\text { tablet (mg O.D.) }\end{array}$ & $\begin{array}{r}\text { Baclofen GRS } \\
\text { capsule (mg O.D.) }\end{array}$ \\
\hline 10 & 30 & 30 \\
(total daily dose $=30 \mathrm{mg}$ ) & 45 & 45 \\
15 & & 60 \\
(total daily dose $=45 \mathrm{mg})$ & 60 & \\
$\begin{array}{l}20 \\
\text { (total daily dose }=60 \mathrm{mg})\end{array}$ & & \\
\hline T.I.D - Three times a day, O.D. - Once a day
\end{tabular}

on 88 patients. Table 2 shows the baseline comparability of the groups. The effects of treatment are displayed in Table 3. Both the treatments caused significant and favorable changes in the efficacy and safety variables from baseline to end of study, but the differences between SR and GRS were not significant. The mean Ashworth score changed significantly $(P=0.00)$ from 3.03 to $2.69(-0.34(-0.49,-0.19))$ for baclofen SR and from 3.07 to $2.70(-0.37 ;(-0.53,-0.22))$ for baclofen GRS [Figure 1]. The 95\% CI of the change in Ashworth score did not cross the $\pm 20 \%$ boundaries of the baseline score in either group (-0.61 to 0.61 ), supporting the hypothesis of their equivalence to the baseline IR therapy at the same daily dosage. Clinical global improvement scores revealed that in the SR and GRS groups, 15 (35\%) and 16 (35\%) patients each, respectively, improved further from baseline, whereas the remainder maintained the same status. The functional improvement was measured from the amount of assistance required by a patient to perform a list of daily activities. The investigator listed three of the most difficult activities per patient based on elicited history. These three activities were collectively rated on a scale of 1 (total assistance) to 7 (complete independence) at baseline and end of the trial. The difference between baclofen IR and baclofen SR was statistically significant, whereas that between baclofen IR and GRS was not. The initial score was $4.26 \pm 1.44$ and $4.33 \pm 1.43$ with IR at baseline, $4.58 \pm 1.34$ and $4.49 \pm 1.39$ with SR and GRS, respectively, at the end of the study. Therefore, the condition of the patients was inclined more toward the less-assistance range.

\begin{tabular}{|c|c|c|}
\hline \multicolumn{3}{|c|}{ Table 2: Baseline comparison of groups ${ }^{*, * *}$} \\
\hline Male/Female & $32 / 13$ & $31 / 12$ \\
\hline Age (year) & $40 \pm 2$ & $43 \pm 2$ \\
\hline Weight (kg) & $56 \pm 1.6$ & $60 \pm 1.6$ \\
\hline \multicolumn{3}{|l|}{ Lesion } \\
\hline Cerebral & 10 & 9 \\
\hline Spinal & 35 & 34 \\
\hline \multicolumn{3}{|l|}{ Etiology } \\
\hline CVA & 10 & 9 \\
\hline MS & 8 & 4 \\
\hline Other spinal & 27 & 30 \\
\hline \multicolumn{3}{|c|}{ Duration of spasticity (years) } \\
\hline$<1$ & 29 & 28 \\
\hline $1-5$ & 15 & 13 \\
\hline$>5$ & 1 & 2 \\
\hline \multicolumn{3}{|c|}{ Extremity affected } \\
\hline Upper & 1 & 0 \\
\hline Lower & 19 & 19 \\
\hline Both & 25 & 24 \\
\hline \multicolumn{3}{|c|}{ Daily baclofen dose at baseline } \\
\hline $30 \mathrm{mg}$ & 33 & 32 \\
\hline $45 \mathrm{mg}$ & 12 & 11 \\
\hline
\end{tabular}




\begin{tabular}{|c|c|c|c|c|}
\hline \multicolumn{5}{|c|}{$\begin{array}{l}\text { Table 3: Efficacy and toleration results for baseline (day } 3 \text { ) and } \\
\text { endpoint (day 31) analysis* }\end{array}$} \\
\hline Variable & Treatment & Baseline & Endpoint & Change \\
\hline \multicolumn{5}{|l|}{ Efficacy } \\
\hline \multirow[t]{2}{*}{$\begin{array}{l}\text { Ashworth } \\
\text { spasticity score }\end{array}$} & SR & $\begin{array}{c}3.03 \\
{[2.82,3.25]}\end{array}$ & $\begin{array}{c}2.69 \\
{[2.50,2.88]}\end{array}$ & $\begin{array}{c}-0.34^{*} \\
{[-0.49,-0.20]}\end{array}$ \\
\hline & GRS & $\begin{array}{c}3.07 \\
{[2.84,3.30]}\end{array}$ & $\begin{array}{c}2.70 \\
{[2.50,2.89]}\end{array}$ & $\begin{array}{c}-0.37^{*} \\
{[-0.53,-0.21]}\end{array}$ \\
\hline \multirow[t]{3}{*}{ Spasm score } & SR & 1.44 & 1.07 & $-0.37^{*}$ \\
\hline & & $\begin{array}{c}{[1.22,1.67]} \\
1.17\end{array}$ & $\begin{array}{c}{[0.90,1.26]} \\
0.99\end{array}$ & $\begin{array}{c}{[-0.61,-0.13]} \\
-0.18^{*}\end{array}$ \\
\hline & ORS & $\begin{array}{c}1.17 \\
{[0.96,1.39]}\end{array}$ & {$[0.82,1.16]$} & $\begin{array}{c}-0.18^{n} \\
{[-0.31,-0.06]}\end{array}$ \\
\hline \multirow[t]{4}{*}{ Reflex score } & SR & 3.38 & 3.12 & $-0.21^{*}$ \\
\hline & & {$[3.05,3.70]$} & {$[2.85,3.48]$} & {$[-0.35,-0.07]$} \\
\hline & GRS & 3.56 & 3.38 & $-0.17^{*}$ \\
\hline & & {$[3.26,3.86]$} & {$[3.09,3.67]$} & {$[-0.32,-0.02]$} \\
\hline \multirow{4}{*}{$\begin{array}{l}\text { Functional } \\
\text { independence } \\
\text { score }\end{array}$} & SR & 4.26 & 4.58 & $0.32^{*}$ \\
\hline & & {$[3.83,4.68]$} & {$[4.18,4.98]$} & {$[0.03,0.61]$} \\
\hline & GRS & 4.33 & 4.49 & 0.16 \\
\hline & & {$[3.89,4.76]$} & {$[4.06,4.91]$} & {$[-0.12,0.48]$} \\
\hline \multirow{4}{*}{$\begin{array}{l}\text { Toleration } \\
\text { Sedation score }\end{array}$} & SR & 10.4 & 6.2 & $-4.2^{*}$ \\
\hline & & {$[7.6,13.2]$} & {$[4.3,8.0]$} & {$[-6.8,-1.6]$} \\
\hline & GRS & 8.1 & 5.3 & $-2.8^{*}$ \\
\hline & & {$[4.9,11.3]$} & {$[3.1,7.6]$} & {$[-5.1,-0.49]$} \\
\hline
\end{tabular}

Mean $(95 \% \mathrm{Cl}) ; n=45$ for SR; $n=43$ for GRS SR - Sustained release; GRS - Gastroretentive system; *Significant at $P<0.05$ within the group; No between-groups difference was significant

One of the objectives of this trial was also to see if there was a difference in the 24-hour round-the-clock efficacy with respect to ease of performing daily activities when the patients were switched over from a three-times a day dose of IR to a once-a-day dose of SR or GRS. A daily diary with a score for the activities of daily life (0-100 on visual analog scale) based on the three most affected activities, recorded at $8 \mathrm{am}, 12 \mathrm{pm}, 4 \mathrm{pm}$, and $8 \mathrm{pm}$ was provided to the patients. The patients' diary scores also showed a significant $(P<0.05)$ reduction in both the groups, the range of baseline-adjusted reduction being 5.3-6.1 on SR and 7.3-8.1 on GRS. The scores were not significantly different between 8 am, 12 pm, 4 pm, and $8 \mathrm{pm}\left(\mathrm{F}_{3,342}=0.1, P=0.96\right)$, indicating little diurnal variation. As for tolerability, there was a statistically significant reduction in the sedation scores from baseline with SR and GRS. The baseline score of $10.36 \pm 9.24$ and $8.14 \pm 10.29$ changed to $6.2 \pm 6.24$ and $5.33 \pm 7.28$ with SR and GRS, respectively. The clinical relevance of this difference may be significant, however, as the scores were not high at baseline, the change is not large and there is a fair amount of variability in scores. In the safety assessment, one patient on SR complained of a moderate tingling sensation in the right and left leg and heaviness of leg, and the other patient on GRS complained of mild urinary incontinence. Neither complaint seemed related to the investigational treatment.

\section{Discussion}

This randomized, controlled, open trial in Indian patients

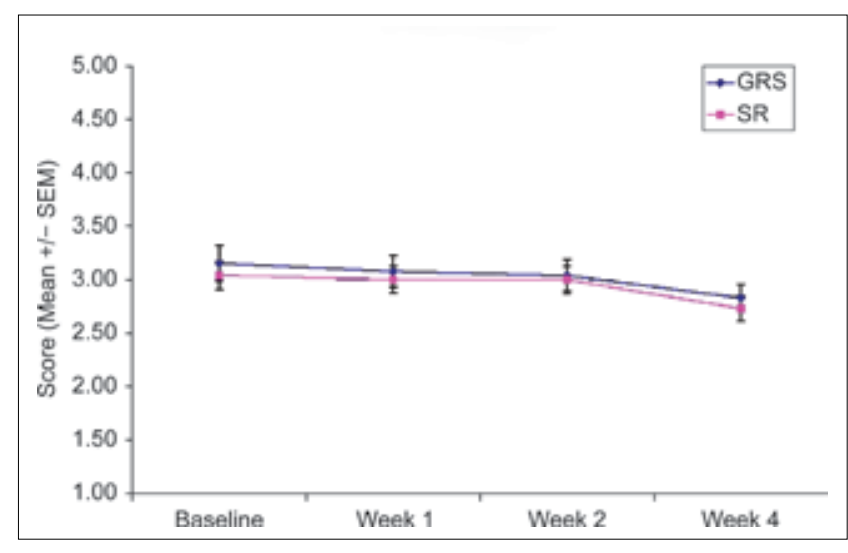

Figure 1: The mean Ashworth score for baclofen sustained release and gastroretentive system at each clinical visit

with neurological spasticity involved treatment with baclofen SR (30/45/60 mg once daily for four weeks) tablets or baclofen GRS (30/45/60 mg once daily for four weeks) capsules. It was conducted across seven sites, with data being pooled for analysis. The purpose of designing the SR and GRS preparations of baclofen was to offer convenient and well-tolerated alternatives to the IR preparation for patients with chronic, neurogenic spasticity. To facilitate switchover at the same total daily dose of IR, dose of baclofen IR was adjusted such that the total daily dose was 30,45 , or $60 \mathrm{mg}$ and the patients were stabilized to this dose regimen for a period of one month. Following switchover to SR or GRS, no dose adjustment was made till the end of the trial. The most common total daily dose of baclofen IR is $30 \mathrm{mg}$. In this trial, $73.86 \%$ of the patients were on $30 \mathrm{mg}$, and $35.38 \%$ on $45 \mathrm{mg}$. None of the patients required a switchover to $60 \mathrm{mg}$. The primary efficacy variable of Ashworth score (tone) showed a statistically significant improvement over baclofen IR with baclofen SR and GRS. The change in score was $0.37 \pm 0.50$ and shows clinical equivalence of IR with GRS and SR. Similarly, there was a statistically significant improvement in spasms and reflexes, the change indicating a clinical equivalence between baclofen IR and GRS/SR. The investigators rated the amount of assistance that a patient would require in performing routine daily activities using the functional improvement measure score and have successfully concluded that majority of the patients remained in the 'minimal assist' range (score 4) where 75\% or more of the tasks can be performed without a helper. The round-the-clock efficacy measured on the basis of the patient diary scores showed statistically significant improvement from IR with GRS and SR. The patient scores remained in the range of 47-58 at all time-points indicating that in spite of a once-a-day dosing, 24-hour efficacy was maintained and there was no trend toward any worsening of disability. The sedation scores for SR and GRS measured at each visit presented a declining pattern from the baseline score of IR. This decrease was statistically significant but as the baseline score was not high, the reduction is not large. 
The low baseline scores may be because these patients had been on baclofen IR for a month or more before the trial and had got adjusted to a certain level of sedation. Both SR and GRS depicted excellent safety profiles with two adverse events reported during the trial, one being moderate tingling sensation in both the legs (SR), and the other, a mild urinary incontinence (GRS). Both the events were classified as not related to the trial drug. The events were mild and did not necessitate stopping of treatment with the trial drug. There were no serious adverse events with any of the treatments.

Thirty three point three-three percent patients on baclofen SR and $37.20 \%$ on baclofen GRS improved with treatment as per investigators global impression, there was no change in $66.66 \%$ and $62.9 \%$ patients, respectively. A majority of patients showing no change indicates the clinical equivalence of GRS and SR with baclofen IR. Thirty five point two-two percent patients showed improvement, which corroborates the improvements seen in efficacy scales. Considering all the parameters evaluated, baclofen SR and GRS are clinically equivalent in efficacy but statistically superior in safety to baclofen IR. Thus, the result of this trial shows that the hypothesis of equivalence is tenable.

\section{References}

1. Prescribing Information Kemstro® (baclofen orally disintegrating tablets).

2. Davidoff RA. Antispasticity drugs: Mechanisms of action. Ann Neurol 1985;17:107-16.

3. Meythaler JM, DeVivo MJ, Hadley M. Prospective Study on the use of bolus intrathecal baclofen for spastic hypertonia due to acquired brain injury. Arch Phys Med Rehabil 1996;77:461-6.

4. Hulme A, MacLennan WJ, Ritchie RT, John VA, Shotton PA. Baclofen in the elderly stoke patient its side-effects and pharmacokinetics. Eur J Clin Pharmacol 1985;29:467-9.

5. Thompson AJ, Jarrett L, Lockley L, Marsden J, Stevenson VL. Clinical management of spasticity. J Neurol Neurosurg Psychiatry 2005;76:459-63.

6. Davis SS. Formulation strategies for absorption windows. Drug Discovery Today 2005;10:249-57.

7. Young RR, Delwaide PJ. Drug therapy: Spasticity. New England Journal of Medicine 1981;304:96-9.

8. Ashworth B. Preliminary trial of carisoprodol in multiple sclerosis. Practitioner 1964;192:540-2.

9. Lataste X, Emre M, Davis C, Groves L. Comparative profile of tizanidine in the management of spasticity. Neurology 1994;44:S53-9.

Accepted on 13-03-2009

Source of Support: Nil, Conflict of Interest: None declared.

\section{Staying in touch with the journal}

1) Table of Contents (TOC) email alert Receive an email alert containing the TOC when a new complete issue of the journal is made available online. To register for TOC alerts go to www.neurologyindia.com/signup.asp.

\section{2) RSS feeds}

Really Simple Syndication (RSS) helps you to get alerts on new publication right on your desktop without going to the journal's website. You need a software (e.g. RSSReader, Feed Demon, FeedReader, My Yahoo!, NewsGator and NewzCrawler) to get advantage of this tool. RSS feeds can also be read through FireFox or Microsoft Outlook 2007. Once any of these small (and mostly free) software is installed, add www.neurologyindia.com/rssfeed.asp as one of the feeds. 